\title{
Tribological Mechanism of Friction and Wear Reduction Using Oil-Based ZnO Nanofluid Applied on Brass
}

\author{
Chuanlin Tao, PhD \\ Bingxu Wang, PhD \\ Gary C. Barber, Professor \\ J. David Schall, Professor \\ Qian Zou, Professor \\ Jing Wang, Professor \\ Automotive Tribology Center, School of Engineering and Computer, \\ Oakland University, Rochester, MI, USA \\ School of Mechanical Engineering Qingdao Technology University, \\ Huangdao Campus, Qingdao
}

Doi: 10.19044/esj.2019.v15n3p223～URL:http://dx.doi.org/10.19044/esj.2019.v15n3p223

\begin{abstract}
In this research, friction and wear characteristics of oil-based $\mathrm{ZnO}$ nanofluid applied on brass disk specimens using a flat-on-flat reciprocating sliding test were studied. Oleic acid was used as surfactant to improve the stability and dispersibility of the $\mathrm{ZnO}$ nanofluid. Metallurgical optical microscopy, scanning electron microscopy and energy-dispersive X-ray spectroscopy were utilized to understand the mechanisms. A $2 \mathrm{wt} \% \mathrm{ZnO}$ nanofluid resulted in $61.1 \%$ reduction in coefficient of friction. Good wear resistance was achieved using low concentrations of $0.5 \mathrm{wt} \%$ and $1 \mathrm{wt} \% \mathrm{ZnO}$ nanofluid. A tribo-film mainly composed of carbon was found inside the wear track, which enhanced the wear resistance and lowered the interface shear strength. This tribo-film was produced by oleic acid which was chemically adsorbed to the brass materials.
\end{abstract}

Keywords: $\mathrm{ZnO}$ nanofluid, oleic acid, coefficient of friction, wear, tribo-film

\section{Introduction}

Nanofluids are stable colloidal suspensions of nano-size particles dispersed in water or oil [Yu et al., 2012]. A number of studies have been conducted to investigate the thermal properties of nanofluids since the presence of nanoparticles can lead to a significant enhancement of thermal 
conductivity [Azimi et al., 2013, Albadr et al., 2013, Minea et al., 2015, sun et al., 2016]. In recent years, the study of nanofluids for potential friction reduction and anti-wear performance has also received great attention. Both friction and wear reduction are strongly dependent on nanoparticle variables such as size, shape, morphology and concentration [Wong et al., 2015, Hu et al., 2005, Hwang et al., 2011, Gara et al., 2012, Wu et al., 2007]. Several potential mechanisms have been reported to explain the enhanced tribological characteristics of nanofluids. Spherical nanoparticles may act as nano-size ball bearings to separate two contacting surfaces. The formation of tribo-film can reduce the coefficient of friction $(\mathrm{COF})$ since some nanoparticles tend to be adsorbed or embedded on surfaces. The nanoparticles can also mend surface defects to improve the load capacity by lowering the local stress concentration in order to protect the surfaces against further catastrophic damage [Gara et al., 2013, Sahoo et al., 2013, Battez et al., 2008, Yu et al., 2008, Xie et al., 2016, Luo et al., 2014].

One of the challenges preventing widespread applications of nanofluids is agglomeration of nanoparticles [Yang et al., 2012, Krishna et al., 2015]. Nanoparticles tend to attract each other because of their relatively large surface area, small particle size and high surface energy. Nanofluids will lose their excellent tribological characteristics once the nanoparticles aggregate into clusters [Mahbubul et al., 2016]. Based on past studies, fatty acid is considered as one of the most effective surfactants used in nanofluid preparation. Acid ions can neutralize the positive charges on particle surfaces to restrain further agglomeration [Parametthanuwat et al., 2011, Saterlie et al., 2012, Ran et al., 2016].

Zinc oxide nanoparticles have displayed good friction reduction and anti-wear behavior as additives in some research studies. Gara and Zou [Gara et al., 2012] conducted pin-on-disk experiments using 1006/1020 round steel disks and 52100 alloy steel balls. Water-based Al2O3 nanofluid reduced the friction but not as much as water-based $\mathrm{ZnO}$ nanofluid. The $\mathrm{Al} 2 \mathrm{O} 3$ nanoparticles produced more abrasive wear due to their high hardness. Gara and Zou [Gara et al., 2013] also reported that a $2 \mathrm{wt} \%$ oil-based $\mathrm{ZnO}$ nanofluid could result in friction and wear reduction in the ball-on-disk test. The $\mathrm{ZnO}$ nanofluid was more effective on smooth surfaces with low load and low sliding speed. A. Hernandez Battez et al. [Battez et al., 2008] found that considerable friction reduction was obtained by using $0.5 \mathrm{wt} \% \mathrm{ZnO}$ and $\mathrm{ZrO} 2$ nanofluids. The deposition of $\mathrm{ZnO}$ and $\mathrm{ZrO} 2$ nanoparticles could be enhanced by increasing the nanoparticle content. Xu et al. [Ran et al., 2016] studied the effect of concentration on tribological performance of $\mathrm{ZnO}$ nanofluids using a four-ball test configuration with 52100 steel balls. The COF and wear were minimum using $0.5 \mathrm{wt} \% \mathrm{ZnO}$ nanofluid. Sophie et al. [Loehle et al., 2014] found that adding $\mathrm{ZnO}$ nanoparticles into poly-alpha-olefin base oil and ionic 
liquid had excellent anti-wear behavior in steel cylinder-on-flat reciprocating tests. They found $2 \mathrm{wt} \% \mathrm{ZnO}$ nanoparticles and $2 \mathrm{wt} \%$ ionic liquid could reduce wear by $61.2 \%$. Tao et al. [Tao et al., 2018] found the tribological performance of $\mathrm{SnO} 2$ nanofluid with oleic acid as surfactant could decrease the COF up to $65.4 \%$ and wear loss up to $43.7 \%$ on brass in flat-on-flat reciprocating sliding tests. A tribo-sintered/embedded patchy film containing $\mathrm{SnO} 2$ was found inside the wear track which lowered the friction and protected the surface against wear.

Most of the previous research studies only considered the tribological characteristics of nanofluids on hard materials such as steel and cast iron [Gara et al., 2013, Sahoo et al., 2013, Battez et al., 2008, Xie et al., 2016]. Few papers considered applications of nanofluids on relatively soft non-ferrous materials, such as copper, brass and aluminum. One important application for soft materials is as the substrate material in bushings. The soft materials used in bushings will be easily worn when a bushing operates in the boundary or mixed lubrication regimes such as occurs during start up and shut down. Nanofluids may have the potential to protect the bushing surfaces during these time periods. In this research, the tribological behavior of oil-based $\mathrm{ZnO}$ nanofluids was investigated on brass by using flat-on-flat reciprocating sliding tests. Oleic acid was used as surfactant to improve the stability and dispersibility of the $\mathrm{ZnO}$ nanofluid. The concentration of nanoparticles was varied to investigate the underlying influences. Metallurgical optical microscopy, scanning electron microscopy (SEM) and energy-dispersive Xray spectroscopy (EDS) were applied to understand the potential mechanisms. The friction and wear reduction mechanism found using $\mathrm{ZnO}$ nanofluids was compared to the mechanism found in previous research using $\mathrm{SnO} 2$ nanofluids.

\section{Experimental Setup}

\section{Experimental Apparatus}

Flat-on-flat reciprocating sliding tests were performed on a Bruker universal micro tribometer (UMT-3), see Figure 1. The brass specimen was submerged in $\mathrm{ZnO}$ nanofluid in a rectangular oil tank during testing. The frictional force was collected at a rate of 100 samples per second. A 3D surface profilometer was used to measure the roughness of the flat specimens before and after testing. An analytical scale with accuracy of $0.1 \mathrm{mg}$ was utilized to measure the initial and final weight of the brass specimens to determine the weight loss. Then the weight loss could be converted into wear volume loss utilizing the brass density of $0.0085 \mathrm{~g} / \mathrm{mm}^{\wedge} 3$. A 400 watt ultrasonic homogenizer with an output frequency of $20 \mathrm{kHz}$ was used to mix the $\mathrm{ZnO}$ nanofluid. An ultrasonic cleaner was employed to clean the upper and lower specimens using acetone before and after each test. SEM with EDS 
and metallurgical optical microscopy were used to examine the worn surfaces and analyze the composition on and off the wear tracks fo determine the mechanisms. The viscosity of the lubricants was measured using a Brookfield DV2T viscometer at a temperature of $20^{\circ} \mathrm{C}$.

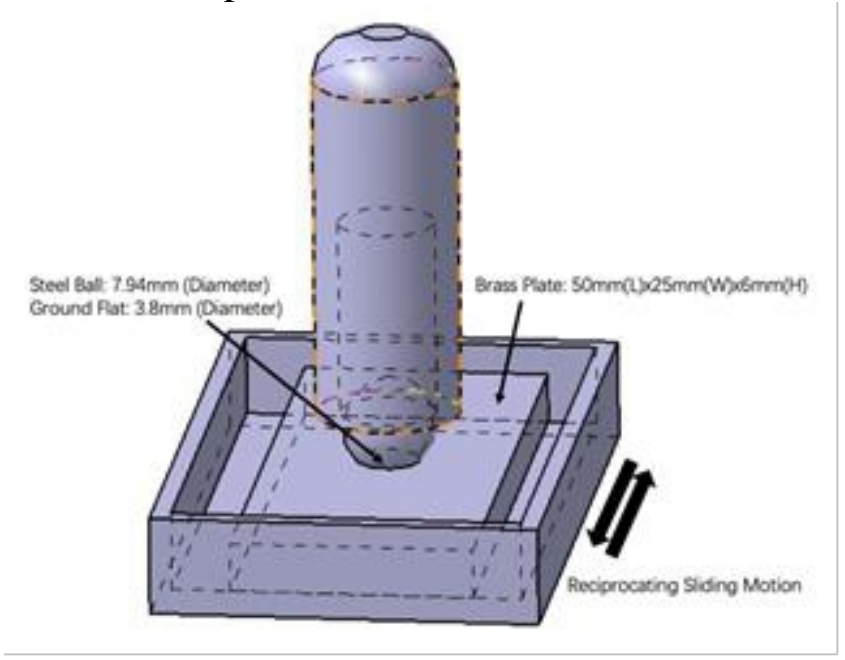

Fig. 1 Flat-on-flat Reciprocating Sliding Test

\section{Test Specimens}

Brass plate was used as the disk specimen, see Figure 2(a), with dimensions of $50 \mathrm{~mm} \times 25 \mathrm{~mm} \times 6 \mathrm{~mm}$. The chemical composition of the brass specimens is shown in Table 1, and the hardness of the brass specimens was HRB59. The flat surface of the upper specimen was produced by grinding the SAE52100 steel bearing ball, which had a diameter of $7.94 \mathrm{~mm}$ and hardness of HRC63, see figure 2(b). The ground flat had a diameter of $3.8 \mathrm{~mm}$. The surface of the brass specimens was ground and polished to produce a surface roughness between $60 \mathrm{~nm}$ and $80 \mathrm{~nm}(\mathrm{Ra})$. The surface roughness of the upper flat steel specimen was approximately $100 \mathrm{~nm}(\mathrm{Ra})$. The base oil was PAO4 (Poly alpha olefin) base oil with a viscosity of $26.8 \mathrm{mpa} \cdot \mathrm{s}$ at $20^{\circ} \mathrm{C}$ and $14.4 \mathrm{mpa} \cdot \mathrm{s}$ at $40^{\circ} \mathrm{C}$. The nanoparticles consisted of $99 \%+$ purity zinc oxide nanoparticles with an average particle size of 40-100nm and surface area ratio of $10-25 \mathrm{~m}^{\wedge} 2 / \mathrm{g}$. Oleic acid (C18H34C2) with a purity of $>97 \%$ and molecular weight of $284.62 \mathrm{~g} / \mathrm{mol}$ was used as the surfactant. 


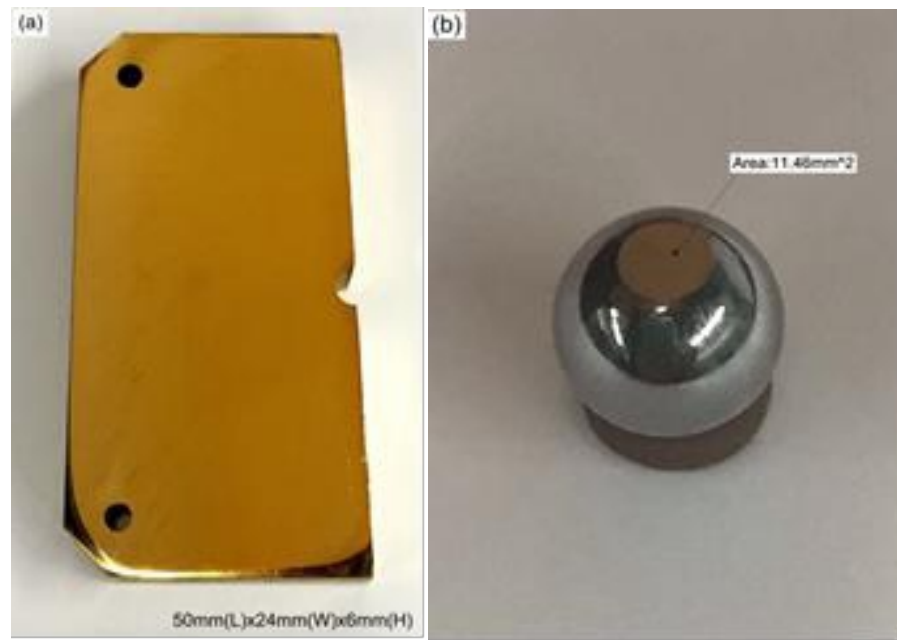

Fig. 2 (a) Brass Plate (b) Flat SAE52100 Steel Ball

Tab. 1 Chemical Composition of Brass Specimen

\begin{tabular}{lccccc}
\hline Element & Copper & Zinc & Lead & Iron & Silicon \\
\hline Percentage & $63 \%$ & $34 \%$ & $2.5 \%$ & $0.3 \%$ & $0.2 \%$ \\
\hline
\end{tabular}

\section{Experimental Procedure}

In the preparation of $\mathrm{ZnO}$ nanofluid, $\mathrm{ZnO}$ nanoparticles, oleic acid and base oil were weighed by an analytical scale to produce different concentrations. The total lubricant volume was approximately $35 \mathrm{ml}$ to ensure the brass specimens could be submerged into the lubricant during testing. Based on previous research [Gara et al., 2013], a wrist shaking machine was utilized for $5 \mathrm{mins}$ followed by ultrasonic homogenization at $320 \mathrm{~W}$ for $5 \mathrm{mins}$ which was sufficient to produce a fully suspended $\mathrm{ZnO}$ nanofluid. A beaker containing cold water $\left(24^{\circ} \mathrm{C}\right)$ was used to maintain the temperature of the nanofluid during the mixing process. Similar preparation steps were used in Guo et al. [Guo et al., 2017]. They reported good stability of $\mathrm{ZnO}$ nanofluids within the first 120mins after the ultrasonic mixing process. Oleic acid and $\mathrm{ZnO}$ nanoparticles were mixed with the same weight ratio. The friction and wear tests were performed within $20 \mathrm{mins}$ after the preparation of the $\mathrm{ZnO}$ nanofluid. The temperature of the $\mathrm{ZnO}$ nanofluid was checked before starting each test in order to eliminate the effects of temperature on tribological performance of the $\mathrm{ZnO}$ nanofluid. The initial test temperature was approximately $26^{\circ} \mathrm{C}$.

In the flat-on-flat reciprocating sliding tests, the displacement was $10 \mathrm{~mm}$ with $1 \mathrm{~Hz}$ frequency, the normal load was $25 \mathrm{~N}$ producing a maximum contact pressure of about $2 \mathrm{MPa}$, and the duration of each test was 360 secs. After the tests were completed, the upper and lower specimens were removed from the test fixture for further wear track and surface topography analysis. 
Each test condition was repeated three times. The COF values reported in this research are average values obtained after a running in period. COF and wear volume loss obtained from the three tests and error bars on figures show the standard deviations.

\section{Results}

\section{Coefficient of Friction and Wear}

Flat-on-flat reciprocating tests were run with pure base oil, base oil with oleic acid only and $\mathrm{ZnO}$ nanoparticles mixed into base oil with oleic acid as surfactant with various concentrations from $0.5 \mathrm{wt} \%$ to $5 \mathrm{wt} \%$. Typical COF versus time plots for base oil with $1 \mathrm{wt} \%$ oleic acid and base oil with $1 \mathrm{wt} \%$ oleic acid and 1wt\% $\mathrm{ZnO}$ nanoparticles (Figure 3) show typical run-in behavior where the drop in COF after the run-in period may correlate with the production of a tribofilm. It can be seen that the run-in period is completed, and the COF reaches a steady state after approximately 80secs. The COF versus time plot for base oil is initially low. The subsequent increase of COF to a high value is due to the occurrence of severe adhesive wear on the interface, see section titled "chemical composition on and off the wear track". The average COF results are shown in Figure 4. The average COF is approximately 0.28 when using pure base oil. The average COF is reduced after adding only oleic acid into base oil, and the $\mathrm{COF}$ reduction becomes more significant with increasing weight percentage of oleic acid in base oil. A $35.6 \% \mathrm{COF}$ reduction is achieved for $5 \mathrm{wt} \%$ oleic acid in base oil. The average $\mathrm{COF}$ continues to decrease after mixing $\mathrm{ZnO}$ nanoparticles and oleic acid in base oil. The optimal weight percentage of $\mathrm{ZnO}$ nanoparticles is $2 \mathrm{wt} \%$, which reduces the average COF by $61.1 \%$.

In Figure 5, it can be seen that the addition of $\mathrm{ZnO}$ nanoparticles and oleic acid produces reduced wear compared with pure base oil under the test conditions utilized in this research. For lubrication using oleic acid in base oil, the wear volume decreases with increasing weight percentage of oleic acid. However, the anti-wear benefits of $\mathrm{ZnO}$ nanoparticles degrade gradually with increasing concentration of $\mathrm{ZnO}$ nanoparticles. The highest wear reduction of $65.5 \%$ occurs with $0.5 \mathrm{wt} \%$ of $\mathrm{ZnO}$ nanoparticles. 


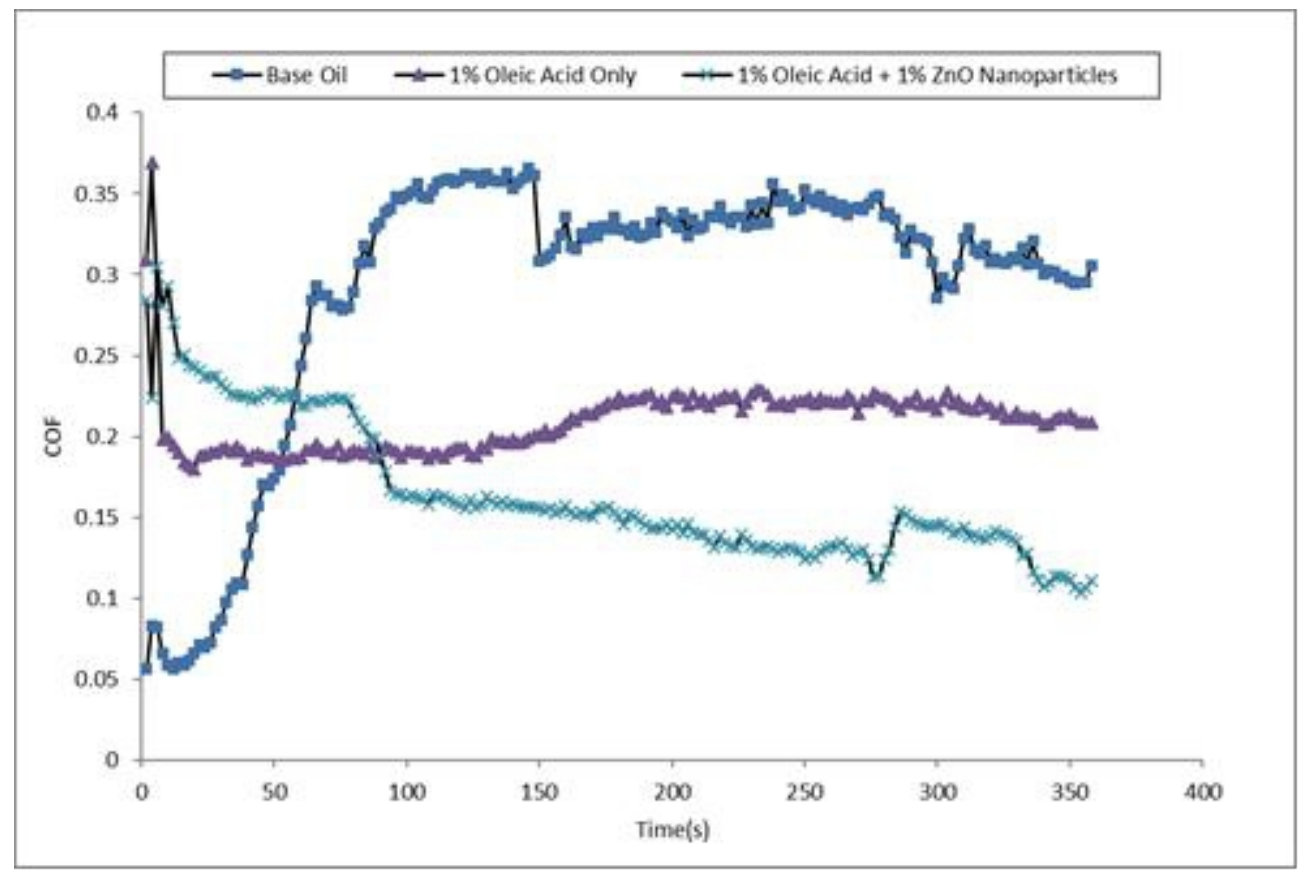

Fig. 3 COF versus Time for Various Lubricants

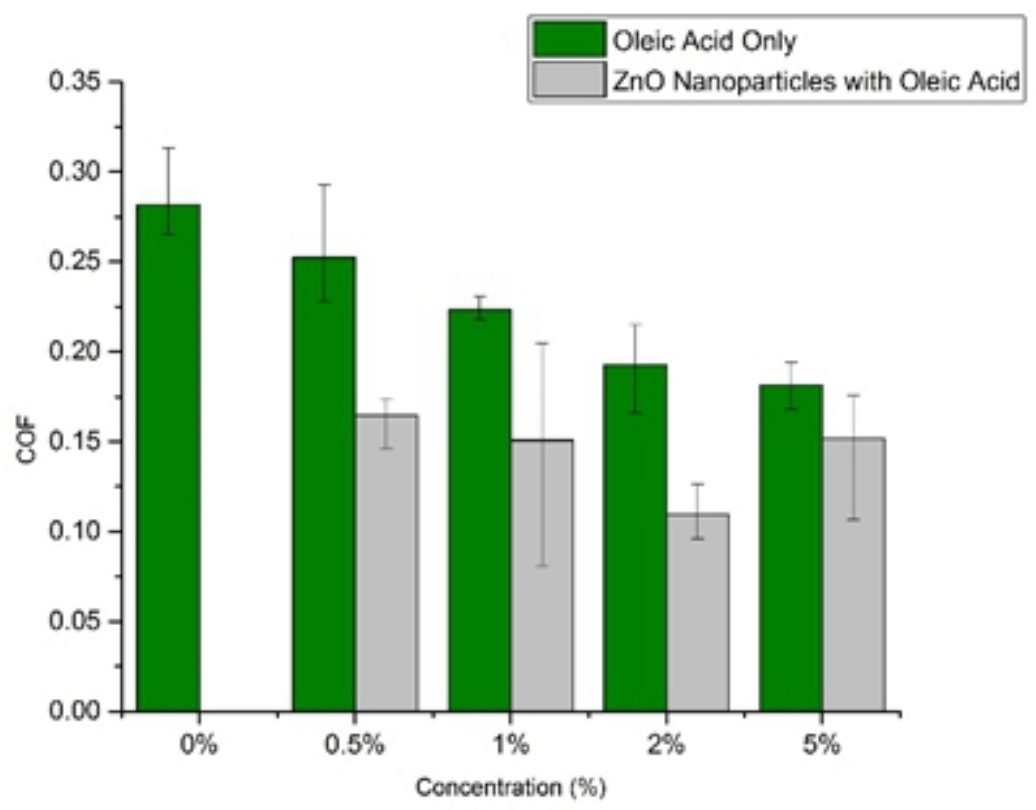

Fig. 4 Effect of Concentrations of Oleic Acid with and without $\mathrm{ZnO}$ Nanoparticles on COF 


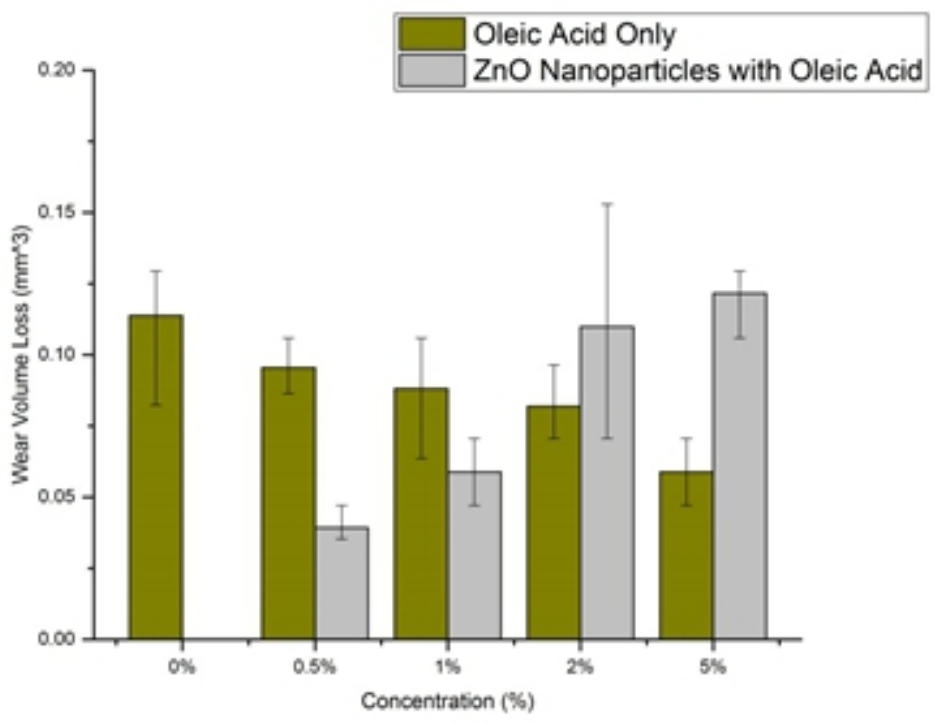

Fig. 5 Effect of Concentrations of Oleic Acid with and without $\mathrm{ZnO}$ Nanoparticles on Brass Wear Volume Loss

Wear Track Analysis

Wear Track Examination by Optical Microscopy and SEM

The primary surface damage on the flat specimens is severe adhesive wear when using pure base oil is likely due to the low hardness of the brass specimen and the inability of the base oil to form a protective tribo-film. The amount of adhesion was so high that it was observed by the naked eye that brass was adhered to the upper steel specimen. In addition, abrasive ploughing is also shown on the brass specimen's wear track since the flat surface of the upper steel specimen is rougher and harder than the lower brass specimen, see Figure 6. The brass material experiences continuous plastic deformation during sliding. When the oleic acid is added into base oil, very little adhesive wear can be found inside the wear track. Grooves are produced on the brass specimen by the asperities on the upper steel specimen. A relatively smooth surface is produced after testing, see Figure 7. Almost no adhesive wear is produced with lubrication using oil-based $\mathrm{ZnO}$ nanofluid. In Figure 8, several wide furrows were produced by $\mathrm{ZnO}$ nanoparticle clusters acting as third-body abrasives between the two mating surfaces or the asperities on the flat surface of the upper steel specimen. Significant dark areas are formed inside the wear track. These dark areas are believed to be a tribo-layer which resulted in lower friction and wear. No wear scars or weight variation was found for the upper flat steel specimen for all tests. 


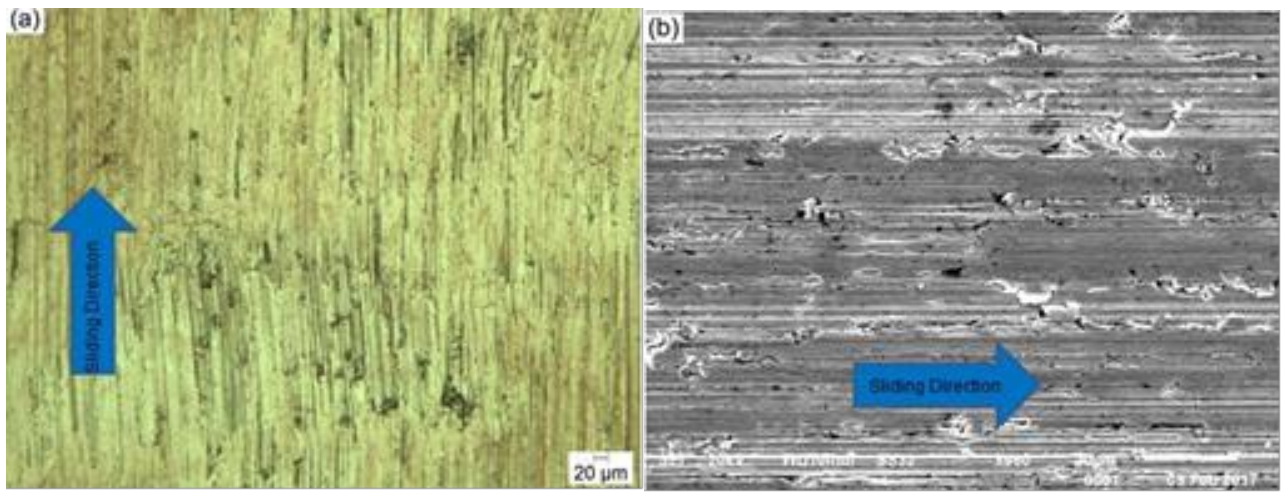

Fig. 6 Surface Morphology of Brass Specimen's Wear Track Using Base Oil (a)

Optical Microscopy (b) SEM
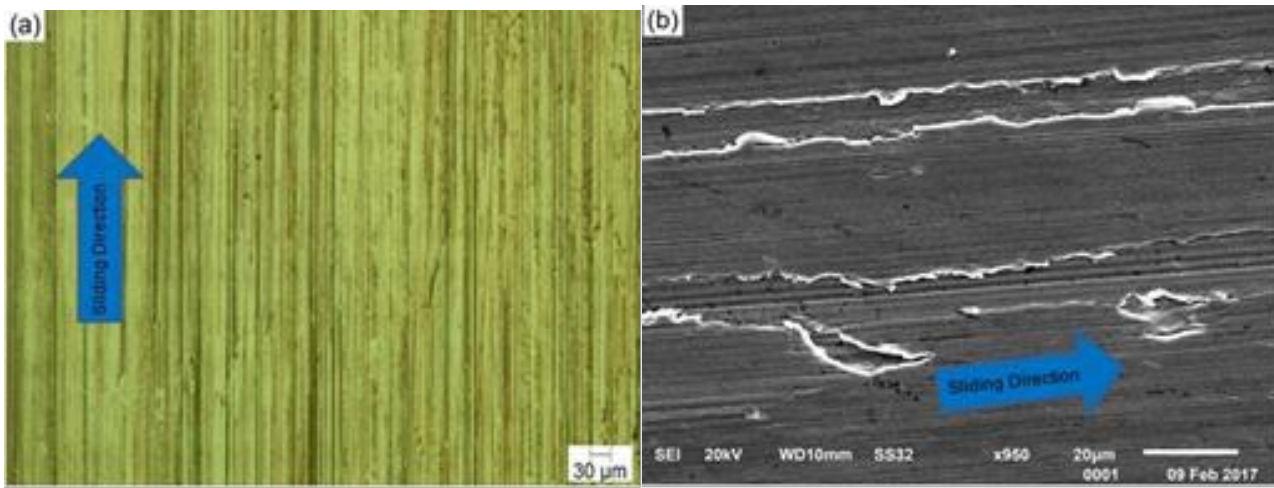

Fig. 7 Surface Morphology of Brass Specimen's Wear Track Using 1wt $\%$ Oleic Acid in Base Oil. (a) Optical Microscopy (b) SEM
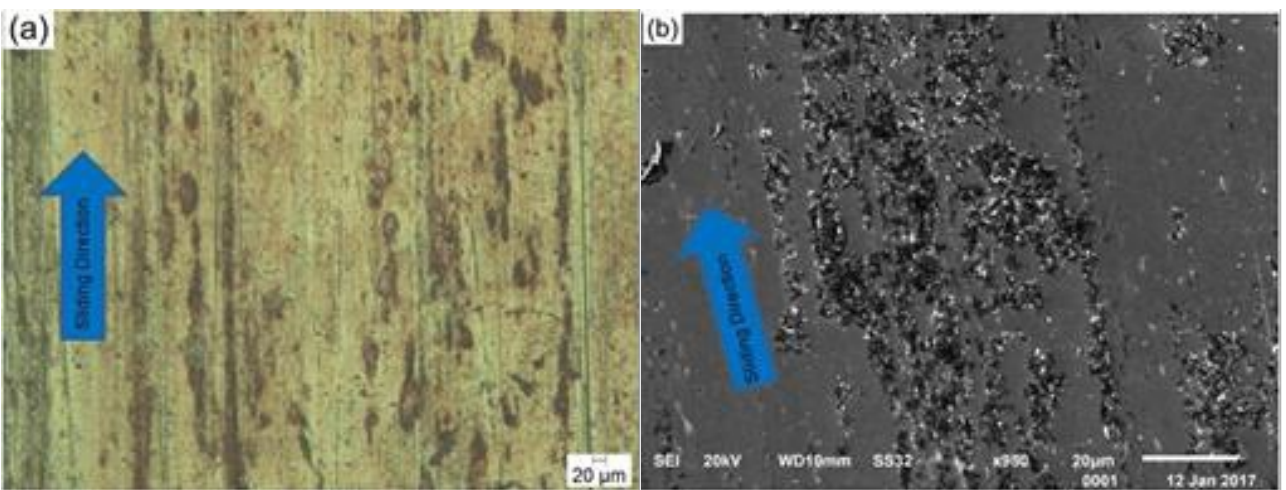

Fig. 8 Surface Morphology of Brass Specimen's Wear Track Using 1wt\% Oilbased ZnO Nanofluid. (a)Optical Microscopy (b) SEM

Chemical Composition On And Off The Wear Track

Surface chemical composition analysis was carried out by using energy-dispersive X-ray spectroscopy (EDS). The flat surface of the steel ball tested with base oil only was analyzed using EDS to verify the wear 
mechanism. The brass specimens tested with base oil with $1 \mathrm{wt} \%$ oleic acid and base oil with $1 \mathrm{wt} \%$ oleic acid and $1 \mathrm{wt} \%$ oil-based $\mathrm{ZnO}$ nanofluid were selected to analyze the function of $\mathrm{ZnO}$ nanoparticles. Measurements were conducted both inside and outside the wear tracks.

In Table 2, it can be seen that copper and zinc were found on the flat surface of the steel ball which were transferred from the brass plate. This confirms that adhesive wear was the primary wear mechanism when using base oil as lubricant. In Table 3, it can be seen with the addition of oleic acid, the atomic percentage of copper was reduced from $13.1 \%$ to $5.4 \%$, which suggested the adhesive wear was reduced significantly. In Table 4, the percentage of carbon increases on the disk wear track run with base oil with $1 \mathrm{wt} \%$ oleic acid as compared to outside the wear track when adding the $1 \mathrm{wt} \%$ oleic acid into base oil. In Table 6 , the percentage of carbon is shown to increase significantly in the black areas when the disk specimen was run with $1 \mathrm{wt} \%$ oil-based $\mathrm{ZnO}$ nanofluid with oleic acid (see Figure 8) when compared with areas off the wear track. However, no detectable carbon could be found on and off the wear track when only using base oil, see Table 5. In Tables 4 and 6 , the atomic percentages of zinc were reduced on the wear track. This is because the total atomic percentage included more carbon and oxygen. The increased carbon content can be ascribed to the oleic acid used in the lubricant. The oleic acid which is an unsaturated fatty acid with an eighteen carbon chain is chemically adsorbed to the substrate by their carboxylic terminal heads to form a protective layer, as illustrated in Figure 9. The motion of $\mathrm{ZnO}$ nanoparticles between the two rubbing surfaces may assist the interaction between oleic acid molecules and brass to activate this formation. $\mathrm{Xu}$ et al. [Xu et al., 1996] described the rolling effects of diamond nanoparticles in the reduction of friction using steel samples. Zou et al. [Gara et al., 2012, Gara et al., 2013] also reported a similar nano-sized bearing effect using oil-based $\mathrm{ZnO}$ and $\mathrm{Al} 2 \mathrm{O} 3$ nanofluids. Mohamed et al. [Mohamed et al., 2018] suggested a nanoball bearing effect between the rubbing surfaces was the potential mechanism to reduce the friction coefficient in the reciprocating sliding contact interface. However, these studies mentioning rolling of nanoparticles did not have direct proof for this mechanism. Although it can not be stated definitely that nanoparticles slide or roll, it can be stated that unless nanoparticles embed into one of the sliding surfaces, they will move both in the contact zone due to the relative movement of the sliding surfaces and outside the contact zone due to agitation of the nanofluid. The high carbon content detected is believed to be due to the long hydrocarbon chain of oleic acid. For this case, the $\mathrm{ZnO}$ nanoparticles may be just the transport medium for this tribo-film formation in flat-on-flat reciprocating tests. This tribo-film is also believed to be produced to a lesser degree when the $\mathrm{ZnO}$ nanoparticles are not present while using oleic acid only in base oil. However, the discolored 
areas are not observed under optical microscopy and SEM when running with base oil only.

The dark areas found when both $\mathrm{ZnO}$ nanoparticles and oleic acid are present may also arise from the incorporation of the $\mathrm{ZnO}$ nanoparticles into the tribofilm. However, the presence of $\mathrm{Zn}$ in the brass makes it difficult to verify whether $\mathrm{ZnO}$ nanoparticles are present in the tribofilm. In Table 6, the atomic percentage of carbon off the wear track was also increased to $36.1 \%$. They might be because the motion of $\mathrm{ZnO}$ nanoparticles produced by the agitation of the nanofluid due to the reciprocating motion of the brass specimen could promote the contact between oleic acid and the brass substrate. Sophie et al. [Loehle et al., 2014] found that addition of a fatty acid such as oleic acid in diesel fuel led to significant reduction of friction on steel at $50^{\circ} \mathrm{C}$. In their research, tribo-film formation was simulated inside the wear track which was caused by the reaction of the carboxylic group with steel. Reeves et al. [Reeves et al., 2012] also concluded that the carbon chains in oleic acid would be "tightly packed" to protect the sliding interface between a copper pin with a hemispherical tip and aluminum and steel composite disk. Martin et al. [Martin et al., 2013] studied the effects of oleic acid on friction reduction in a reciprocating cylinder-on-flat sliding tests. A tribo-film was formed producing low friction. They did not determine the composition of the tribofilm.

Similar test conditions and brass samples were used in previous research [Tao et al., 2018] regarding the characteristics of anti-wear and friction reduction of $\mathrm{SnO} 2$ nanofluids. In the previous research, the $\mathrm{COF}$ and wear volume loss could be reduced up to $65.4 \%$ and $43.7 \%$, respectively. A tribo-sintered or embedded patchy tribo-film containing tin element was detected inside the wear track. In the current research with $\mathrm{ZnO}$ nanofluids, the wear volume loss was improved by $61.1 \%$ using $0.5 \mathrm{wt} \% \mathrm{ZnO}$ nanofluids. A tribo-film with a high carbon percentage was found inside the wear track which was caused by chemical adsorption of oleic acid. The $\mathrm{ZnO}$ nanoparticles might not be firmly embedded into brass to form a protective film since no significant percentage of zinc was detected by EDS analysis. Instead, $\mathrm{ZnO}$ nanoparticles may just act as a medium to transport the carbon chains of oleic acid to the brass.

In most of the previous nanofluid research, hard steel and cast iron were used as substrate materials. In the study of nanofluids on hard materials, few researchers have reported any tribo-film composed of carbon. In the previous research using $\mathrm{ZnO}$ nanoparticles [Tao et al., 2018], 2.05\% Sn element was found to be embedded inside the wear track accompanied with the increased percentage of $\mathrm{C}$ from $2.13 \%$ to $8.41 \%$. Hence, the carboxylic group in the carbon chain seemed to be more apt to react with brass than steel or cast iron to form a tribo-film. 
Viscosity of Lubricants

The viscosities of base oil, base oil with oleic acid and base oil with oleic acid and $\mathrm{ZnO}$ nanoparticles are shown in Figure 10. At a temperature of $20^{\circ} \mathrm{C}$, the addition of oleic acid into the base oil caused only a slight increase in viscosity. For the oleic acid and $\mathrm{ZnO}$ nanofluid, the viscosity of lubricant is increased significantly when adding $2 \%$ and $5 \% \mathrm{ZnO}$ nanoparticles into base oil. The sliding surfaces are in the mixed regime so an increase of viscosity will also contribute to the reduction of friction when using the base oil, oleic acid and $\mathrm{ZnO}$ nanoparticle nanofluid.

Tab. 2 Chemical Composition on Flat Surface of Steel Ball Run with Base Oil

\begin{tabular}{cc}
\hline Element & Atomic\% \\
\hline $\mathrm{Fe}$ & 47.6 \\
$\mathrm{Cu}$ & 13.1 \\
$\mathrm{Zn}$ & 5.1 \\
$\mathrm{C}$ & 0 \\
$\mathrm{O}$ & 34.2 \\
\hline
\end{tabular}

Tab. 3 Chemical Composition on Flat Surface of Steel Ball Run with 1wt\% Oleic Acid

\begin{tabular}{cc}
\multicolumn{2}{c}{ and Base Oil } \\
\hline Element & Atomic\% \\
\hline $\mathrm{Fe}$ & 63.8 \\
$\mathrm{Cu}$ & 5.4 \\
$\mathrm{Zn}$ & 0 \\
$\mathrm{C}$ & 0 \\
$\mathrm{O}$ & 30.8 \\
\hline
\end{tabular}

Tab. 4 Chemical Composition on and off the Brass Specimen Wear Track Run with $1 \mathrm{wt} \%$ Oleic Acid with Base Oil

\begin{tabular}{ccc}
\hline Element & $\begin{array}{c}\text { Off the Wear Track } \\
\text { Atomic\% }\end{array}$ & $\begin{array}{c}\text { On the Wear Track } \\
\text { Atomic\% }\end{array}$ \\
$\mathrm{C}$ & 10.4 & 18.1 \\
$\mathrm{O}$ & 5.3 & 8.5 \\
$\mathrm{Cu}$ & 54.2 & 50.6 \\
$\mathrm{Zn}$ & 30.0 & 22.6 \\
\hline
\end{tabular}

Tab. 5 Chemical Composition on and off the Brass Specimen Wear Track Run with

\begin{tabular}{ccc}
\multicolumn{3}{c}{ Base Oil } \\
\hline Element & $\begin{array}{c}\text { Off the Wear Track } \\
\text { Atomic\% }\end{array}$ & $\begin{array}{c}\text { On the Wear Track } \\
\text { Atomic\% }\end{array}$ \\
$\mathrm{C}$ & 0 & 0 \\
$\mathrm{O}$ & 37.3 & 41.2 \\
$\mathrm{Cu}$ & 37.9 & 45.8 \\
$\mathrm{Zn}$ & 24.8 & 13 \\
\hline
\end{tabular}


Tab. 6 Chemical Composition on and off the Brass Specimen Wear Track Run with 1wt\% Oil-based $\mathrm{ZnO}$ Nanoparticles with $1 \mathrm{wt} \%$ Oleic Acid

\begin{tabular}{ccc}
\hline Element & $\begin{array}{c}\text { Off the Wear Track } \\
\text { Atomic\% }\end{array}$ & $\begin{array}{c}\text { On the Wear Track } \\
\text { Atomic\% }\end{array}$ \\
$\mathrm{C}$ & 36.1 & 62.9 \\
$\mathrm{O}$ & 7.4 & 9.8 \\
$\mathrm{Cu}$ & 36.0 & 16.8 \\
$\mathrm{Zn}$ & 20.3 & 10.4 \\
\hline
\end{tabular}

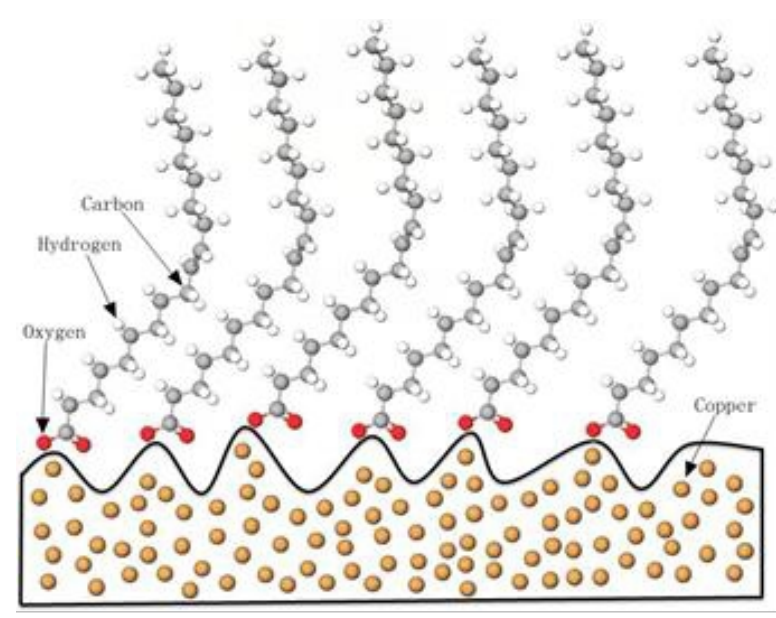

Fig. 9 Chemisorption of Oleic Acid on Brass Surface

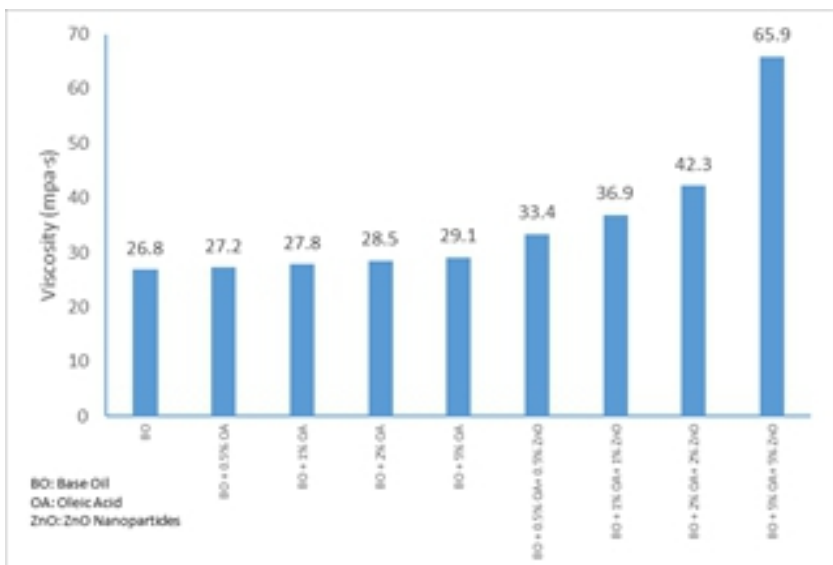

Fig. 10 Viscosity of Base Oil, Base Oil with Oleic Acid and Base Oil with Oleic Acid and $\mathrm{ZnO}$ nanoparticles at $20^{\circ} \mathrm{C}$

\section{Conclusion and Summary}

After testing the tribological characteristics of oil-based $\mathrm{ZnO}$ nanofluid with oleic acid as surfactant on brass using flat-on-flat reciprocating tests, the following conclusions can be summarized:

Oil-based $\mathrm{ZnO}$ nanofluid with oleic acid as surfactant reduced the COF as compared to pure base oil and base oil with oleic acid only on flat-on-flat 
reciprocating tests for the concentrations used in this research. The $2 \mathrm{wt} \% \mathrm{ZnO}$ nanofluid reduced the $\mathrm{COF}$ by $61.1 \% .0 .5 \mathrm{wt} \% \mathrm{ZnO}$ nanoparticles reduced the wear volume loss by $65.5 \%$.

A tribo-film was detected inside the wear track of samples run with base oil with oleic acid and samples run with base oil with oleic acid and $\mathrm{ZnO}$ nanoparticles, which was mainly composed of carbon. Oleic acid with a long hydrocarbon and carboxylic terminal head may be chemically adsorbed to the brass material. This tribo-film led to improved wear resistance and lower COF. The increased viscosity of the nanofluid when $\mathrm{ZnO}$ nanoparticles are used also contributed to the reduction in COF.

Compared to the previous tests using $\mathrm{ZnO}$ nanofluids on hard metals such as cast iron and steel [Gara et al., 2012, Gara et al., 2013, Battez et al., 2008], the $\mathrm{ZnO}$ nanoparticles seemed to be a transport medium for the formation of protective carbon tribo-film rather than playing an essential role for the friction and wear reduction for brass.

\section{References:}

1. Yu, W., \& Xie, H. (2012). A Review on Nanofluids: Preparation, Stability Mechanisms, and Applications. Journal of Nanomaterials, https://doi.org/10.1155/2012/435873.

2. Azimi, M., \& Ommi, F. Using Nanofluid for Heat Transfer Enhancement in Engine Cooling Process. (2013). Journal of Nano Energy and Power Research J Nano Energy Power Res, 2(2), 132-134. doi:10.1166/jnepr.2013.1017.

3. Albadr, J., Tayal, S., \& Alasadi, M. (2013). Heat Transfer Through Heat Exchanger Using Al2O3 Nanofluid at Different Concentrations. Case Studies in Thermal Engineering, 1(1), 38-44. doi:10.1016/j.csite.2013.08.004.

4. Minea, A. A. (2015). Numerical Studies on Heat Transfer Enhancement and Synergy Analysis on Few Metal Oxide Water Based Nanofluids. International Journal of Heat and Mass Transfer, 89, 1207-1215.

5. Sun, B., Peng, C., Zuo, R., Yang, D., \& Li, H. (2016). Investigation on the Flow and Convective Heat Transfer Characteristics of Nanofluids in the Plate Heat Exchanger. Experimental Thermal and Fluid Science, 76, 75-86.

6. Wong, K. V., \& Leon, O. D. (2015). Applications of Nanofluids: Current and Future. Advances in Mechanical Engineering, 2(0), 519659-519659.

7. $\mathrm{Hu}, \mathrm{X}$. (2005). On the Size Effect of Molybdenum Disulfide Particles on Tribological Performance. Industrial Lubrication and Tribology, 57(6), 255-259. 
8. Hwang, Y., Lee, C., Choi, Y., Cheong, S., Kim, D., Lee, K., Lee, J., Kim, S. H. (2011). Effect of the Size and Morphology of Particles Dispersed in Nano-oil on Friction Performance between Rotating Discs. Journal of Mechanical Science and Technology J Mech Sci Technol, 25(11), 2853-2857. doi:10.1007/s12206-011-0724.

9. Gara, L., \& Zou, Q. (2012). Friction and Wear Characteristics of Water-Based $\mathrm{ZnO}$ and $\mathrm{Al} 2 \mathrm{O} 3$ Nanofluids. Tribology Transactions, 55(3), 345-350.

10. Wu, Y., Tsui, W., \& Liu, T. (2007). Experimental Analysis of Tribological Properties of Lubricating Oils with Nanoparticle Additives. Wear, 262(7-8), 819-825.

11. Gara, L., \& Zou, Q. (2013). Friction and Wear Characteristics of OilBased ZnO Nanofluids. Tribology Transactions, 56(2), 236-244. doi:10.1080/10402004.2012.740148.

12. Sahoo, R. R., Bhattacharjee, S., \& Das, T. (2013). Development of Nanofluids as Lubricant to Study Friction And Wear Behavior of Stainless Steels. International Journal of Modern Physics: Conference Series Int. J. Mod. Phys. Conf. Ser., 22, 664-669. doi:10.1142/s2010194513010829.

13. Battez, A. H., González, R., Viesca, J., Fernández, J., Fernández, J. D., Machado, A., Chou, R., Riba, J. (2008). CuO, $\mathrm{ZrO} 2$ and $\mathrm{ZnO}$ Nanoparticles as Anti-wear Additive in Oil Lubricants. Wear, 265(34), 422-428. doi:10.1016/j.wear.2007.11.013.

14. Yu, H., Xu, Y., Shi, P., Xu, B., Wang, X., \& Liu, Q. (2008). Tribological Properties and Lubricating Mechanisms of $\mathrm{Cu}$ Nanoparticles in Lubricant. Transactions of Nonferrous Metals Society of China, 18, 636-641.

15. Xie, H., Jiang, B., Liu, B., Wang, Q., Xu, J., \& Pan, F. (2016). An Investigation on the Tribological Performances of the SiO2/MoS2 Hybrid Nanofluids for Magnesium Alloy-Steel Contacts. Nanoscale Research Letters, 11(1). doi:10.1186/s11671-016-1546-y.

16. Luo, T., Wei, X., Huang, X., Huang, L., \& Yang, F. (2014). Tribological Properties of A12O3 Nanoparticles as Lubricating Oil Additives. Ceramics International, 40(5), 7143-7149. doi:10.1016/j.ceramint.2013.12.050.

17. Yang, Y., Oztekin, A., Neti, S., \& Mohapatra, S. (2012). Particle Agglomeration and Properties of Nanofluids. Journal of Nanoparticle Research J Nanopart Res, 14(5). doi:10.1007/s11051-012-0852-2.

18. Krishna, K. H., Neti, S., Oztekin, A., \& Mohapatra, S. (2015). Modeling of Particle Agglomeration in Nanofluids. J. Appl. Phys. Journal of Applied Physics, 117(9), 094304. doi:10.1063/1.4913874. 
19. Mahbubul, I.; Saidur, R.; Amalina, M.; Niza, M. (2016). International Communications in Heat and Mass Transfer, 76, 33-40.

20. Parametthanuwat, T., Rittidech, S., Pattiya, A., Ding, Y., \& Witharana, S. (2011). Application of Silver Nanofluid Containing Oleic Acid Surfactant in A Thermosyphon Economizer. Nanoscale Res Lett Nanoscale Research Letters, 6(1), 315. doi:10.1186/1556-276x-6-315.

21. Saterlie, M. S., Sahin, H., Kavlicoglu, B., Liu, Y., \& Graeve, O. A. (2012). Surfactant Effects on Dispersion Characteristics of CopperBased Nanofluids: A Dynamic Light Scattering Study. Chemistry of Materials, 24(17), 3299-3306. doi:10.1021/cm203853f.

22. Ran, X., Yu, X., \& Zou, Q. (2016). Effect of Particle Concentration on Tribological Properties of $\mathrm{ZnO}$ Nanofluids. Tribology Transactions, 60(1), 154-158. doi:10.1080/10402004.2016.1154233.

23. Loehle, S., Matta, C., Minfray, C., Mogne, T. L., Martin, J., Iovine, R., Obara, Y., Miura, R., Miyamoto, A. (2014). Mixed Lubrication with C18 Fatty Acids: Effect of Unsaturation. Tribology Letters, 53(1), 319328. doi:10.1007/s11249-013-0270-3.

24. Tao, C., Wang, B., Barber, G., Schall, D., \& Lan, H. (2018). Tribological Behavior of $\mathrm{SnO} 2$ Nanoparticles as an Oil Additive on Brass. Lubrication Science, 30, 247-255.

25. Guo, J., Barber, G., Schall, D., Zou, Q., \& Jacob, S. (2017). Tribological Properties of $\mathrm{ZnO}$ and WS2 Nanofluids Using Different Surfactants. Wear, 382-383, 8-14. https://doi.org/10.1016/j.wear.2017.04.003.

26. Xu, T., Zhao, J., \& Xu, Z. (1996). The Ball-bearing Effect of Diamond Nanoparticles as an Oil Additive. Journal of Physics D: Applied Physics, 2932-2937, 29.

27. Mohamed, A., Hou, X., Fadl, E., Mohamed, A., Ahmed, E., \& S.W. S. (2018). Friction and Wear Reduction Mechanisms of the Reciprocating Contact Interfaces Using Nanolubricant Under Different Loads and Speeds. Journal of Tribology, 140-5. doi:10.1115/1.4039720.

28. Reeves, C., Menezes, P., Jen, T., \& Lovell, M. (2012). Evaluating the Tribological Performance of Green Liquid Lubricants and Powder Additives Based Green Liquid Lubricants. Proceedings of the STLE 2012 Annual Meeting \& Exhibition.

29. Martin, J., Matta, C., Bouchet, M., Forest, C., Mogne, T., Dubois, T., \& Mazarin, M. (2013). Mechanisms of Friction Reduction of Unsaturated Fatty Acids as Additives in Diesel Fuels. Friction, 1(3), 252-258. https://doi.org/10.1007/s40544-013-0022-2. 